\title{
COMPARISON OF MULTIPLE CARRIER DISPOSITION PWM TECHNIQUES APPLIED FOR MULTI-LEVEL SHUNT ACTIVE FILTER
}

\author{
Sebasthi Rani Kathalingam* — Porkumaran Karantharaj ${ }^{* *}$
}

\begin{abstract}
This work presents the simulation of a shunt active filter using seven-level cascaded inverter. The ultimate objective is to bring out the influence of multiple carrier level shifted PWM techniques on the performance of a shunt active filter. Classical disposition PWM techniques such as PD, POD and APOD have been used to generate the gating signals for the inverter active switches. A comparison is presented to substantiate the effect of these techniques in filtering. The comparison is made from the perspective of reduction in THD of source currents after filtering. For compensation current extraction synchronous detection method has been used. The harmonic reduction is achieved in source currents as well as source voltages.
\end{abstract}

K e ywords: power quality, point of common coupling (PCC), detection method (SDM), multi-level inverter, total harmonic distortion (THD)

\section{INTRODUCTION}

The power quality studies have always been hot topic for electrical engineers. Power quality has received a great deal of attention lately, with the increased use of power electronic converters in adjustable speed drives, uninterruptible power supplies etc. These power electronic converters are Non-Linear loads which draw nonlinear currents from the source and hence cause distortion in the voltage wave form at the point of common coupling. This will affect the voltage and current sensitive devices at the PCC. There are power quality standards that define the maximum allowable limit of distortion in voltage and current waveforms of the power supply. Traditional controllers such as passive filters, synchronous capacitors and phase advancers include many disadvantages such as fixed compensation, bulkiness, electromagnetic interference, possible resonance etc. These disadvantages urged electrical engineers to develop adjustable and dynamic solutions using custom power devices. Custom power devices are power conditioning equipments using static power electronic converters. Active power filter is one of the most important remedial measures to solve such power quality problems [1]. Nowadays shunt active power filters, due to their flexibility and reliability are versatile and efficient solutions in the compensation of the load power factor and current harmonics. This work makes an attempt to study and compare the compensation characteristics of a synchronous detection based multilevel shunt active filter for different Disposition PWM techniques.

\section{BASIC CONFIGURATION OF THE ACTIVE FILTER}

Shunt active Filter acts as a current source injecting equal but opposite harmonic and quadrature components of load current at the point of common coupling. In effect the system views nonlinear load together with active filter as an ideal resistor. A PWM Voltage source inverter operating as a current controlled device can be used as SAF. Latest researches include the use of Multi-level inverter for high power energy conversion. Multilevel inverters do not need a coupling transformer to interface it with high power system. The advantages of the multilevel inverter will enable the circuit to operate with less output voltage harmonics and less electromagnetic interference. The modular structure of cascade H-bridges helps us to increase the output voltage levels as per the requirements. There are individual capacitors for each H-bridge module. There are $N$ voltage sources per phase for a $2 N+1$ level inverter [2]. Figure 1 shows the structure of proposed shunt active power filter.

The control circuitry uses Synchronous detection method for reference compensating current extraction. Its ability to achieve improvement in both source voltage and source current waveforms was already proved unlike other SAF control methods. Here the SAF uses all the three basic Carrier Disposition techniques for Modulation of Inverter.

\section{MULTILEVEL INVERTER TOPOLOGY}

A cascaded multilevel inverter is made up from series connected single-phase full bridge inverters, each with their own isolated dc bus. This multilevel inverter can

\footnotetext{
* Department of Electrical and Electronics Engg., Sri Ramakrishna Engineering College, Coimbatore-641 022 Tamilnadu, India ** Principal, Dr NGP Institute of Technology, Coimbatore-641 048 Tamilnadu, India
} 


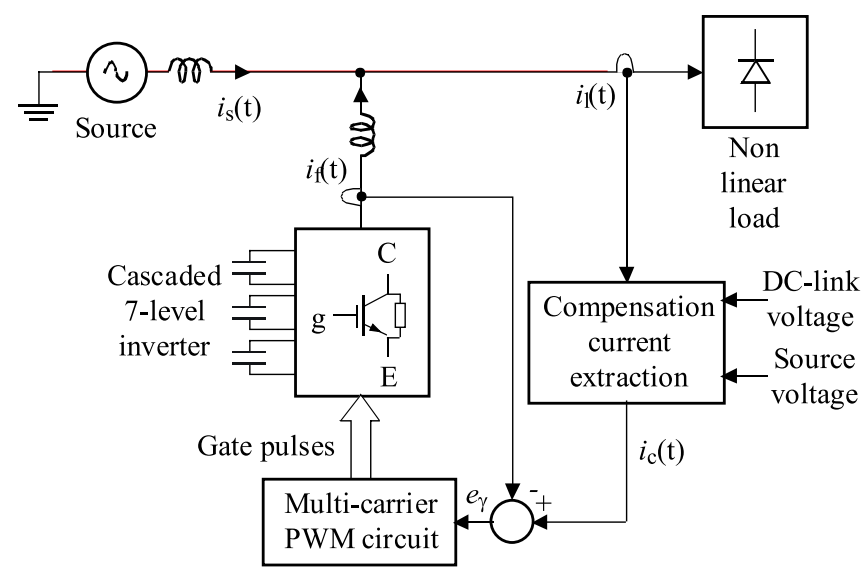

Fig. 1. Basic Configuration of the Active Filter

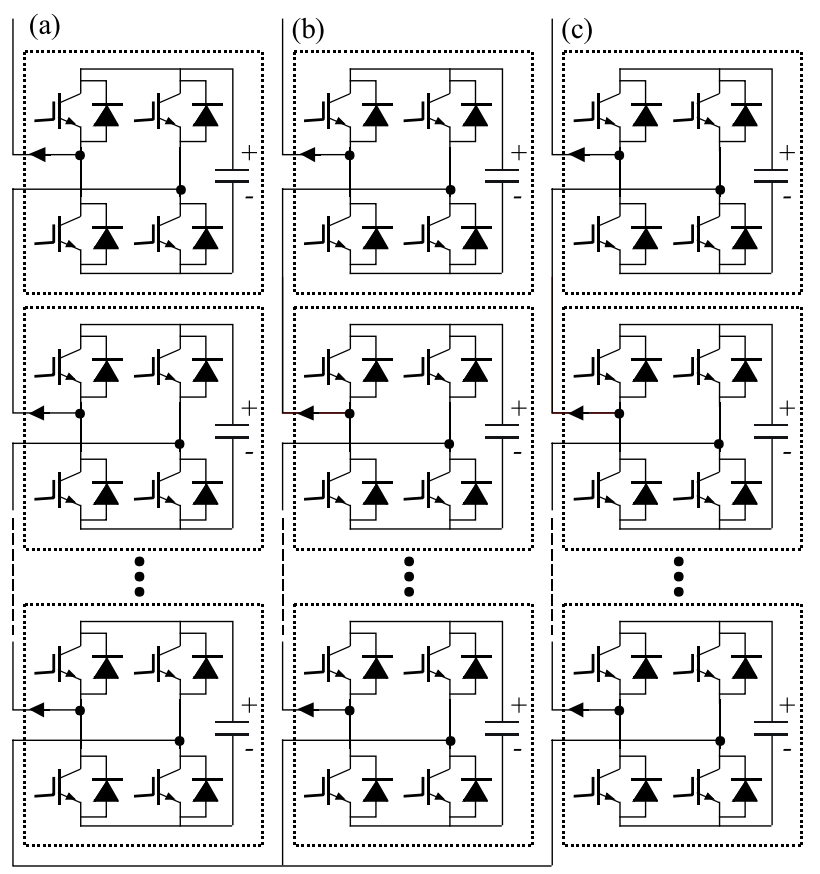

Fig. 2. Power circuit diagram of a cascaded seven level inverter

generate almost sinusoidal waveform voltage from several separate dc sources, which may be obtained from solar cells, fuel cells, batteries, ultra capacitors, etc. This type of converter does not need any transformer or clamping diodes or flying capacitors. Each level can generate three different voltage outputs $+\mathrm{Vdc}, 0$ and $-\mathrm{Vdc}$ by connecting the dc sources to the ac output side by different combinations of the four switches. The output voltage of an M-level inverter is the sum of all of the individual inverter outputs. Each of the H-bridges active devices switches only at the fundamental frequency, and each $\mathrm{H}-$ bridge unit generates a quasi-square waveform by phaseshifting its positive and negative phase legs switching timings. Further, each switching device always conducts for $180^{\circ}$ (or $1 / 2$ cycle) regardless of the pulse width of the quasi-square wave so that this switching method results in equalizing the current stress in each active device. This topology of inverter is suitable for high voltage and high power inversion because of its ability to synthesize waveforms with better harmonic spectrum and low switching frequency. Figure 2 shows the power circuit of a 7 level cascaded inverter composed of three full bridge inverters connected in series on each phase.

Considering the simplicity of the circuit and advantages, Cascaded H-bridge topology is chosen for the presented work. A multilevel inverter has four main advantages over the conventional bipolar inverter $[2,3]$. First, the voltage stress on each switch is decreased due to series connection of the switches. Therefore, the rated voltage and consequently the total power of the inverter could be safely increased. Second, the rate of change of voltage $(\mathrm{d} V / \mathrm{d} t)$ is decreased due to the lower voltage swing of each switching cycle. Third, harmonic distortion is reduced due to more output levels. Fourth, lower acoustic noise and electromagnetic interference (EMI) is obtained.

\section{COMPENSATING CURRENT CALCULATION}

The compensating currents are calculated here using a simple algorithm called Synchronous Detection. In synchronous detection method (SDM), the average real power consumed by the load with respect to the three phases gives the desired mains currents, assuming them to be balanced and in-phase with the supply voltages after compensation. The reference compensation signals are then derived as the difference between the load currents and the desired mains currents $[7,8]$. The compensating currents are calculated taking into account the magnitudes of per phase voltages. SDM method is basically used for the determination of amplitude of the source currents. In this algorithm, the three-phase mains currents are assumed to be balanced after compensation [9]. The real power $P(t)$ consumed by the load could be calculated from the instantaneous voltages and load currents as

$$
P(t)=\left[\begin{array}{lll}
V_{s a}(t) & V_{s b}(t) & V_{s c}(t)
\end{array}\right]\left[\begin{array}{lll}
I_{l a}(t) & I_{l b}(t) & I_{l c}(t)
\end{array}\right]^{\top},
$$

where $V_{s a}(t), V_{s b}(t), V_{s c}(t)$ are the instantaneous values of supply voltages and $I_{l a}(t), I_{l b}(t), I_{l c}(t)$ are the instantaneous values of load currents. The average value $P_{d c}$ is determined by applying $P(t)$ to a low pass filter. The real power is then split into the three phases

$$
\begin{aligned}
P_{a} & =\frac{P_{d c} V_{\text {arms }}}{V_{\text {arms }}+V_{b r m s}+V_{c r m s}}, \\
P_{b} & =\frac{P_{d c} V_{b r m s}}{V_{\text {arms }}+V_{b r m s}+V_{c r m s}}, \\
P_{c} & =\frac{P_{d c} V_{c r m s}}{V_{\text {arms }}+V_{b r m s}+V_{c r m s}} .
\end{aligned}
$$

For purely sinusoidal balanced voltages,

$$
P_{a}=P_{b}=P_{c}=\frac{P_{d c}}{3}
$$




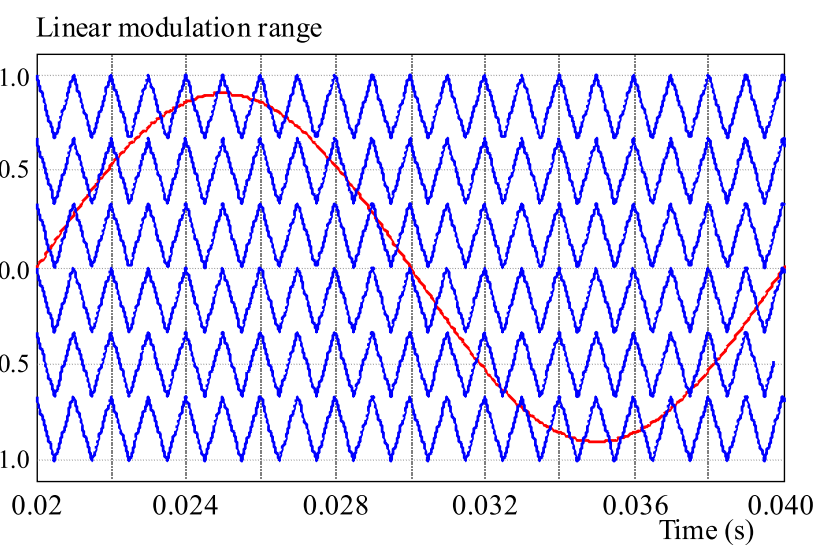

Fig. 3. Illustration of PD Method with Level shifted carrier signals of frequency $1 \mathrm{KHz}$, and sinusoidal Modulating signal of frequency $50 \mathrm{~Hz}$

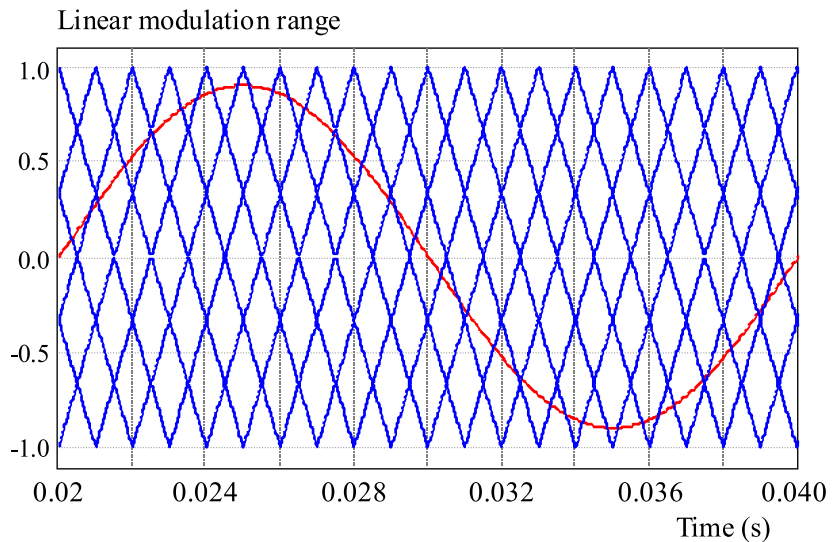

Fig. 5. Illustration of APOD Method with Level shifted carrier signals of frequency $1 \mathrm{KHz}$, and sinusoidal Modulating signal of frequency $50 \mathrm{~Hz}$

Table 1. Simulation parameters

\begin{tabular}{ll}
\hline Sending end voltage (line to neutral) & $415 \mathrm{v}(\mathrm{rms})$ \\
System frequency & $50 \mathrm{~Hz}$ \\
Value of filter inductor & $5 \mathrm{mH}$ \\
Load impedance & $R=35 \Omega$, \\
Carrier frequency for PWM circuit & $L=15 \mathrm{mH}$ \\
Value of dc-link capacitor & $2400 \mu \mathrm{KH}$ \\
\hline
\end{tabular}

With the objective of achieving Unity Power Factor (UPF), the desired mains currents are obtained by equations (6), (7) and (8).

$$
\begin{aligned}
I_{s a} & =\frac{2 V_{s a}(t) P_{a}}{V_{a r m s}^{2}}, \\
I_{s b} & =\frac{2 V_{s b}(t) P_{b}}{V_{b r m s}^{2}}, \\
I_{s c} & =\frac{2 V_{s c}(t) P_{c}}{V_{c r m s}^{2}},
\end{aligned}
$$

where $V_{\text {arms }}, V_{\text {brms }}, V_{\text {crms }}$ are the amplitudes of the supply voltages. The compensation currents are calcu-

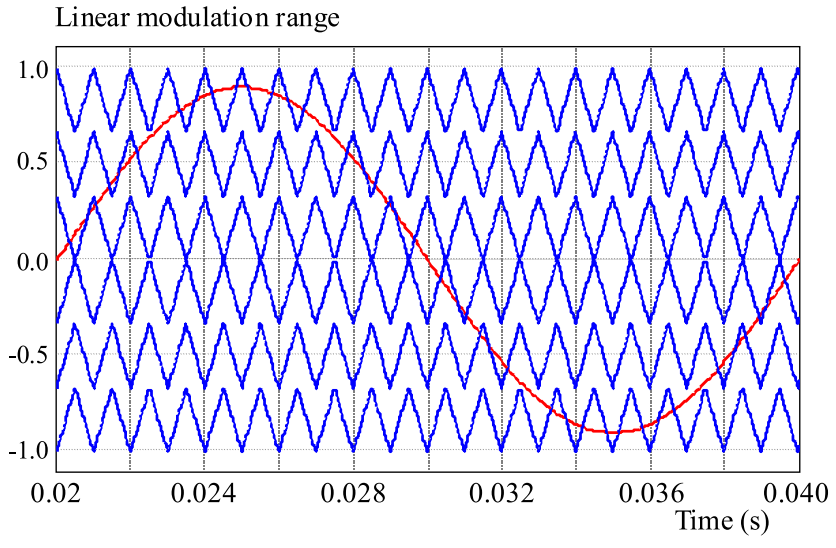

Fig. 4. Illustration of POD Method with Level shifted carrier signals of frequency $1 \mathrm{KHz}$, and sinusoidal Modulating signal of frequency $50 \mathrm{~Hz}$

lated using equations (6), (7) and (8).

$$
\begin{gathered}
I_{c a}(t)=I_{s a}(t)-I_{l a}(t), \\
I_{c b}(t)=I_{s b}(t)-I_{l b}(t), \\
I_{c c}(t)=I_{s c}(t)-I_{l c}(t) .
\end{gathered}
$$

\section{MULTIPLE CARRIER DISPOSITION PWM}

Carrier based disposition PWM methods were first proposed by Carrara et al [3]. Previous works on PWM techniques shows that disposition technique for diode clamped and PSCPWM for cascaded inverters give rise to same harmonic profile for the same number of total switch transitions [4]. Hence these techniques can be efficiently applied for Diode Clamped and Cascaded Multilevel Inverters. The main classification of carrier based PWM techniques are Phase shifted carrier PWM and Carrier disposition PWM. Most of the carrier based PWM techniques have been derived from the classical carrier disposition strategies. The phases of carrier signals are rearranged to produce three main disposition techniques known as PD, POD and APOD. Carrier Disposition method arrange $N-1$ carrier waveforms of same amplitude and frequency in continuous bands to fully occupy the linear modulation range of the inverter. The reference or modulating wave is positioned at the centre of the carrier set, and continuously compared with the carriers. Whenever the magnitude of reference wave is greater than a carrier wave, positive going switching pulse is obtained. When the reference goes above all the carriers maximum output is obtained. As the reference falls below each carrier the corresponding levels in the inverter output gets reduced. Carrier arrangements and corresponding switching patterns generated by seven-level Disposition PWM are illustrated in Figs. 3-5.

\subsection{Phase disposition technique}

In phase disposition method (Fig. 3) all the carriers have the same frequency and amplitude. Moreover all the $N-1$ carriers are in phase with each other. They differ only in DC offset. 
Table 2. Simulation results

\begin{tabular}{|c|c|c|c|c|c|c|c|c|c|}
\hline & \multicolumn{3}{|c|}{ PD PWM } & \multicolumn{3}{|c|}{ POD PWM } & \multicolumn{3}{|c|}{ APOD PWM } \\
\hline & \multicolumn{9}{|c|}{ Phase } \\
\hline & $\mathrm{a}$ & $\mathrm{b}$ & $\mathrm{c}$ & $\mathrm{a}$ & $\mathrm{b}$ & $\mathrm{c}$ & $\mathrm{a}$ & $\mathrm{b}$ & $\mathrm{c}$ \\
\hline Magnitude of source voltage (V) & 319.6 & 319.8 & 319.7 & 319.5 & 319.7 & 319.7 & 319.8 & 319.9 & 319.9 \\
\hline THD of source voltage ( $\%$ of fundamental) & 0.21 & 0.21 & 0.22 & 0.22 & 0.22 & 0.21 & 0.21 & 0.20 & 0.19 \\
\hline Magnitude of source current (A) & 26.47 & 26.21 & 26.3 & 26.54 & 26.29 & 26.34 & 26.17 & 26.01 & 25.98 \\
\hline THD of source current ( $\%$ of fundamental) & 3.56 & 3.47 & 3.72 & 3.66 & 3.67 & 3.53 & 3.44 & 3.31 & 3.19 \\
\hline
\end{tabular}

\subsection{Phase opposition disposition technique}

Here carriers above the zero reference point are out of phase with those below zero reference point by $180^{\circ}$ (Fig. 4). Frequency and amplitude of carrier waves are the same but they differ in DC offset.

\subsection{Alternate phase opposition disposition tech- nique}

In APOD Method (Fig. 5) all the carriers have the same amplitude, frequency and different DC offset. Each carrier is phase shifted by $180^{\circ}$ from the adjacent carrier.

\section{SIMULATION}

The system considered for simulation is a three phase balanced source of $415 \mathrm{~V}$. A seven-level shunt active filter has been constructed and simulated in MATLAB/ SIMULINK environment. Table-1 shows the parameters used for simulation.

A diode rectifier feeding an $R-L$ load acts as nonlinearload. Three phase source voltages and load currents are measured at the point of common coupling and fed to the synchronous detection circuitry. It gives the necessary compensating currents. These currents are continuously compared with the filter currents for proper tracking. The error signals thus produced are fed to the level shifted PWM Circuitry. Simulation is done for PD, POD and APOD Modulation techniques. Table 2 shows the simulation results of seven-level cascaded shunt active filter for all the three level-shifted PWM techniques. A comparison of the simulation results reveals that there is not much variation in the results when $\mathrm{PD}$ and POD methods are used. There is no significant difference between average value of percentage THDs of source current in all the three phases for PD and POD methods. Though, PD method shows slightly better result than POD. Significant reduction in THD of source currents is found for APOD PWM technique. It gives far better results than the other two methods.

Figures 6, 7(a) and 7(b) show simulated waveforms of the filter. There is noticeable reduction of source voltage harmonics after compensation. It is clearly inferred from the wave forms that power factor is also compensated approximately to unity. APOD modulation Technique optimizes the source current THD from an uncompensated value of $26 \%$ (of fundamental component) to $3.19 \%$ compared to other Disposition techniques.
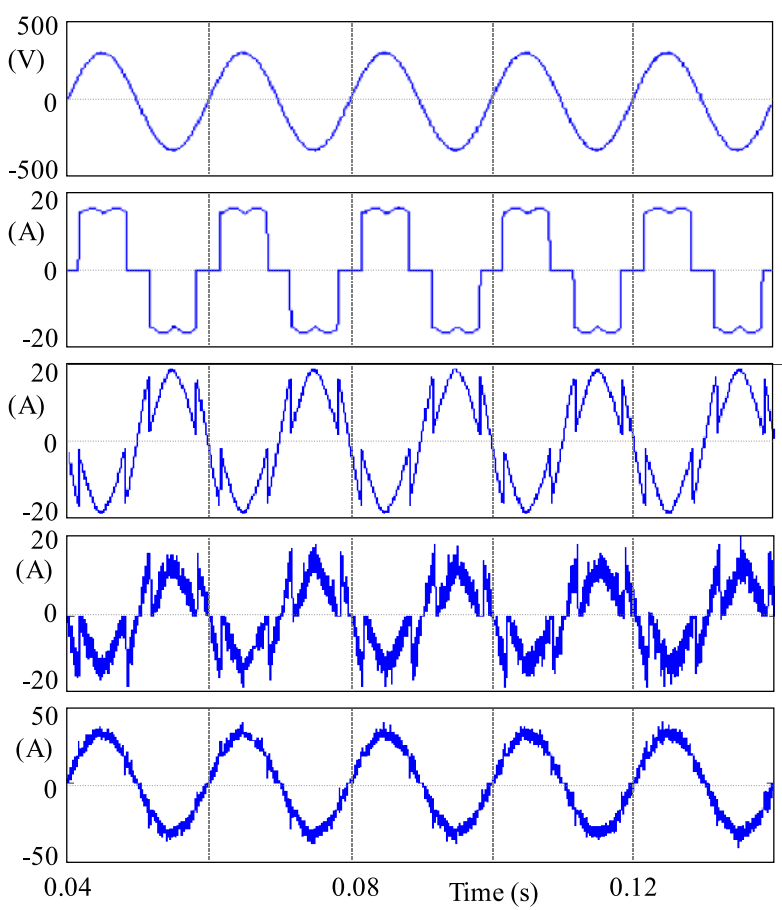

Fig. 6. Simulation results of the Shunt Active Filter after compensation using PD PWM Method (i) Source voltage (ii) Load current (iii) Reference compensation current (iv) Actual filter current (v) Source current

\section{CONCLUSIONS}

From the MATLAB/SIMULINK based simulation of the Multilevel Shunt Active Filter, results were obtained for all the three classical carrier disposition PWM techniques. Comparison of outputs gives the idea that results are optimized for APOD PWM Method. In addition it has been observed that the Disposition techniques can be successfully used for Cascaded inverters with same efficiency as that of Diode clamped Inverters. Harmonic polluted system is found to be well responding to proposed active filter. THD of the source current meets the IEEE 519 standards after compensation. 

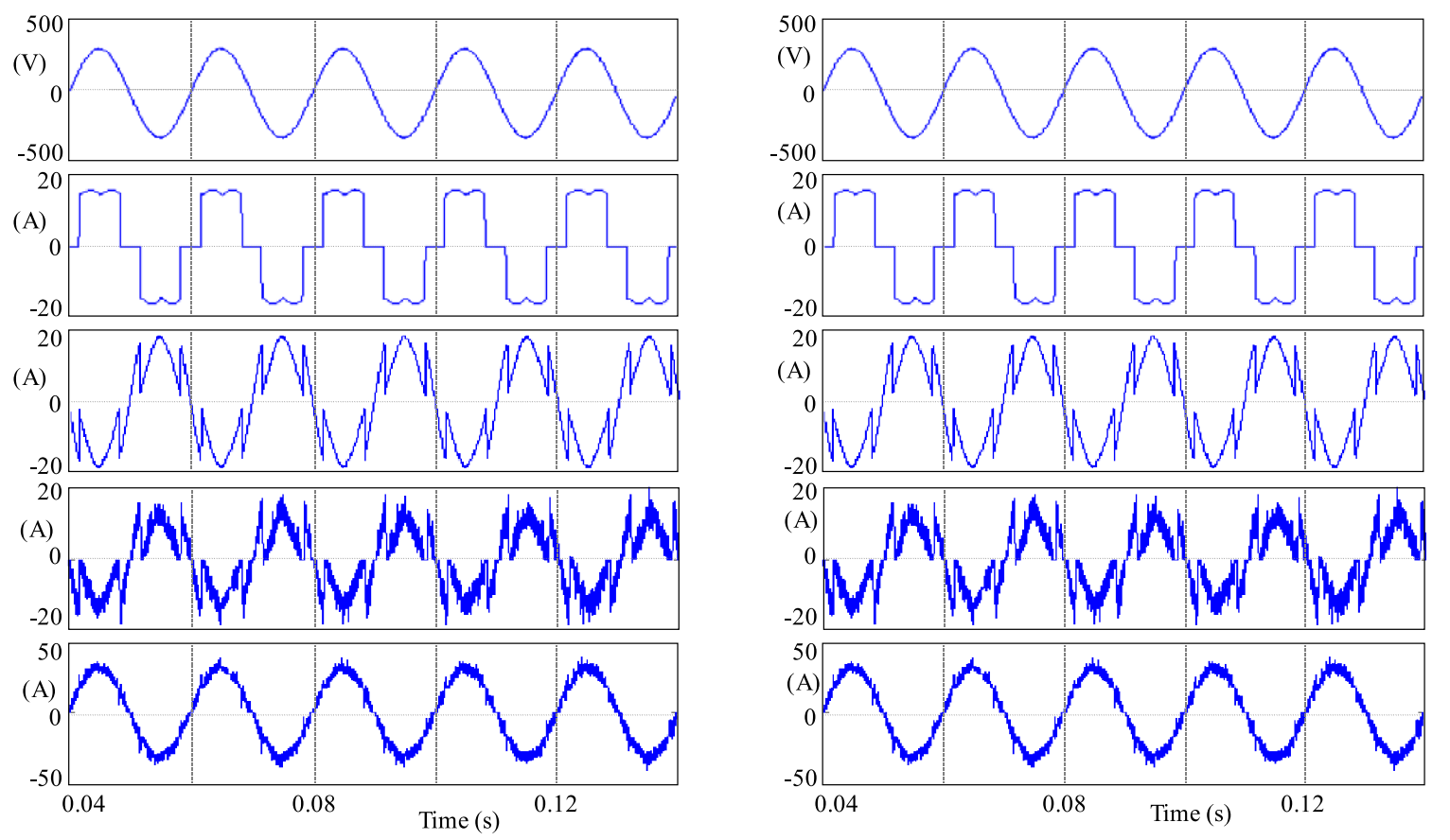

Fig. 7. (a) Simulation results of the Shunt Active Filter after compensation using POD PWM Method (i) Source voltage (ii) Load current (iii) Reference compensation current (iv) Actual filter current (v) Source current (b) Simulation results of the Shunt Active Filter after compensation using APOD PWM Method (i) Source voltage (ii) Load current (iii) Reference compensation current (iv) Actual filter current (v) Source current

\section{REFERENCES}

[1] SINGH. B.-Al-HADDAD, K.-CHANDRA, A.: A review of Active Filters for Power Quality Improvement, IEEE Transactions on Industrial Electronics 46 No. 5 (Oct 1999), 960-971.

[2] PENG, F. Z.-LAI, J. S.-McKEEVER, J.-Van COEVERING, J.: A Multilevel Voltage-Source Inverter with Separate DC Sources for Static Var-Generation, IEEE Transactions on Industrial Applications 32 (1996), 1130-1138.

[3] CARRARA, G.-GARDELlA, S.-MARCHESONI, M.-SALUTARI, R.-SCIUTTO, G. : A New Multilevel PWM Method: a Theoretical Analysis, IEEE Transactions on Power Electronics 7 (1992), 497-505.

[4] AGELIDIS-CALAIS, M.: Application Specific Harmonic Performance Evaluation of Multi-Carrier PWM Techniques, in Conf. Rec. 1998 IEEE Power Electronics Specialists Conference, p. 172178.

[5] ENJeTI, P. N.-ZIOGAS, P. D.: Programmed PWM Techniques to Eliminate Harmonics: A Critical Evaluation, IEEE Trans. On Industry Application 26 No. 2 (Mar/Apr 1990), 418-430.

[6] McGRATH, B. P.-HOLMES, D. G.: Multi-carrier PWM strategies for Multilevel Inverters, IEEE Transactions on Industrial Electronics 49 No. 4 (Aug 2002).

[7] HOLMES, D. G.-McGRATH, B. P.: Opportunities for Harmonic Cancellation with Carrier based PWM for Two-Level and Multilevel Cascaded Inverters, in conf. Rec. IEEE/IAS Annual Meeting, 1999.

[8] LIN, C. E.-CHEN, C. L.-HUANG, C. L.: Calculating Approach and Implementation for Active Filters in Unbalanced Three Phase System using Synchronous Detection Method, IEEE, IECON92, San Diego, Nov 19-21, 1992, pp. 374-380.

[9] NAIR, M. G.-BHUVANESWARI, G. : A Novel Shunt Active Filter Algorithm Simulation and Analog Circuit based Implementation, Special issue on Power Quality, International Journal of Energy Technology and Policy (IJETP) 4, 1/2 (2006), $118-125$.
[10] MOLEYKUTTY, G.-BASU, K. P. : Three-Phase Shunt Active Power Filter, American Journal of Applied Sciences 5 No. 8 (2008), 909-916.

11] ABAALI, $\mathrm{H}$ et al: Shunt Active Power Filter Control under Non-Ideal Voltage Conditions, International Journal of Information Technology 2 No. 2 (2005).

Received 21 September 2011

Sebasthi Rani Kathalingam received BE degree in Electronics and Communication Engineering and ME degree in power electronics and drives from Government College of Engineering, Tirunelveli, India, in 1996 and 2005 respectively and is currently pursuing $\mathrm{PhD}$ degree in electrical engineering from Anna University, Coimbatore. With 13 years of experience in teaching she is currently working as a Assistant Professor in electrical and electronics engineering department of Sri Ramakrishna Engineering College, Coimbatore, India. Her field of interests includes power quality, power electronics and electrical drives.

Porkumaran Karantharaj received BE degree in instrumentation and control engineering from A. K. College of engineering, Srivilliputur, India in 1995, ME and PhD degrees in Electrical and Electronics engineering from PSG College of Technology, Coimbatore, India. After 16 years of teaching and research experience, he is a professor and Vice Principal of Dr.NGP Institute of Technology, Coimbatore, Tamilnadu, India. He is a faculty advisor of instrument society of India (ISOI), IISC, Bangalore and reviewer of International journal of intelligent system technology and applications (IJISTA) and AMSE, France. His fields of interests include control systems, neural networks fuzzy logic systems, and image processing. He has won several awards including outstanding scientist of $21^{\text {st }}$ century by international biographical centre of Cambridge, England. 